How to cite: Bălăceanu, C., Drăgulinescu, A.-M., Bosoc, S., Orza, O., Suciu, G. (2021) Monitoring the Vineyard Health Using Internet of Things Sensors in Smart Agriculture - a Technical Report. 2021 " Air and Water Components of the Environment" Conference Proceedings, Cluj-Napoca, Romania, p. 131-140, DOI: 10.24193/AWC2021_12.

\title{
MONITORING THE VINEYARD HEALTH USING INTERNET OF THINGS SENSORS IN SMART AGRICULTURE - A TECHNICAL REPORT
}

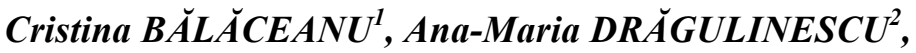 \\ Sabina BOSOC ${ }^{1}$, Oana ORZA ${ }^{1}$, George $S U C I U^{1}$
}

DOI: 10.24193/AWC2021_12

\begin{abstract}
In the last decade, massive implementation of detection devices that use the Internet of Things (IoT) has penetrated considerably in all areas, and the agricultural field is no exception. The article aims to provide an integrated vineyard management solution based on the Internet of Things technology in the Smart Viticulture domain. The monitored parameters for Smart Agriculture are the air temperature and humidity and soil and air humidity, which have a direct impact on grapes. The study region is at the viticulture station and the study period was from June to September in two the year 2019-2020. Vineyard perimeter includes the plantations located both on the right bank of the river Târnava Mare and on the river Târnava Mică, in a hilly area with kneaded relief, but very favorable for the culture of vines. The most common diseases of the vineyards are powdery mildew, downy mildew, and bunch rot. Moreover, the monitoring system aims to manage agricultural issues related to irrigations and analyze the measured parameters' effect, helping the farmers have healthy vineyards. Also, the paper addresses the need to achieve climate-adapted and more resilient farming, promoting better management tools based on objective data-driven decisions.
\end{abstract}

Keywords: IoT, Smart Agriculture, vineyard, sensors.

\section{INTRODUCTION}

Climate change can influence agricultural plants, which are vulnerable to weather conditions. The incidence of vine diseases is increased by higher temperatures and changes in the rainfall area, leading to crop damage. Current IoT and Cloud Computing developments have led to the growth in different agricultural environments, including disease detection and pesticide management detection. IoT physical parameter analysis systems help farmers and growers maximize their crop

\footnotetext{
1 Beia Consult International, Research Department, Peroni street no 16, Bucharest, Romania (cristina.balaceanu@beia.ro)

2 University Politehnica of Bucharest, Telecomunications Department, Bucharest, Romania (ana.dragulinescu@upb.ro)
} 
yields and promote their crops' health. The weather conditions in which particular grape varieties are grown affect the maturity of the grapes and the wine's quality. Climate change has left its mark on viticulture in recent years through abrupt temperature changes and heavy precipitation or drought (Caroll and Wilcox 2003).

Changes in weather patterns (30 years on average), such as air and soil temperature and humidity fluctuations, late spring frosts, and early autumn frosts, floods, and drought, contribute to some diseases affecting grapes. These thermal variations in grapes and wine quality mean that growers no longer have a success rate.

The paper presents the key IoT technologies used in precision farming, usercentered analysis, and architectural design. Lee et al., in 2013 proposed a monitoring framework for grapes that includes a decision-making tool to enhance the analysis of harvest statistics and their connection with the crop information monitored. The system consists of three components: the vineyard monitoring subsystem (IoT Service), the prediction system for statistics, and the text mining technology-based analysis system. Smart Viticulture is a fully integrated approach covering the quality of soil and the wetness of leaves (Libelium site).

In the research carried out by Irimia et al., developed within the international project TERVICLIM (Univ. Rennes 2, France), a climate monitoring network of wine-growing areas with observation points was created in 20 vineyards in 13 countries. The data are recorded by thermal sensors in the Cotnari vineyard. The project is based on small-scale analysis of climate change in vineyards, using temperature loggers (Tinytag TK-4014). They are located in vineyards at various latitudes. Trilles et al. have developed a standard platform (SEnviro), with sensors with low hardware costs. The platform is equipped with temperature, relative humidity and precipitation sensors for vineyard monitoring and is based on GPRS. These parameters are analyzed to detect downy mildew according to the Goidanich model.

Perez-Exposito et al., in 2017 suggested a tracking framework that offers historical and real-time values of different applicable environmental parameters, providing data that could help to take concrete steps to improve the efficiency of treatments. Besides, as pests and their host plants are interdependent, it helps to forecast the effects of climate-driven changes. Therefore, this approach is an Internet of Things (IoT) era hardware and software framework for remote monitoring of vineyards. The suggested device is a wireless sensor network based on Wi-Fi, consisting of autonomous and self-powered nodes deployed within a vineyard. The transmission of data is carried out by the presence of sensor nodes that collect data and then send it to a software network. Data is sent to the MQTT (Message Queuing Telemetry Transport) broker as messages. This protocol is used because it is important to remotely access nodes' networks, so the network bandwidth is limited (Oliver et al., 2018).

The remainder of this paper is structured as follows: the applied methods are summarized in Section II. The observations and discussion are outlined in Section III, and Section IV consists of aspects relevant to conclusions and future work. 


\section{DATA AND METHODS}

\subsection{Case Study}

The case study was realized in a vinicultural region near Blaj. The Blaj Wine Center (Fig. 1) is located at the intersection of the geographical coordinate's $46^{\circ} 10^{\prime} 31^{\prime \prime} \mathrm{N}$ latitude and $23^{\circ} 54^{\prime} 52^{\prime \prime} \mathrm{E}$ longitude (Calugar et al. 2018). The vineyard perimeter in this region is very favorable for vine cultivation.

The specific ecoclimatic conditions in Târnave Vineyard allow the production of high quality dry, semi-sweet or sweet wines, semi-aromatic and aromatic wines and sparkling wines. Tarnave vineyard, the biggest viticulture area from Transilvania, is known and appreciated for its quality wines with a specific flavour and a good sugar/acidity balance.
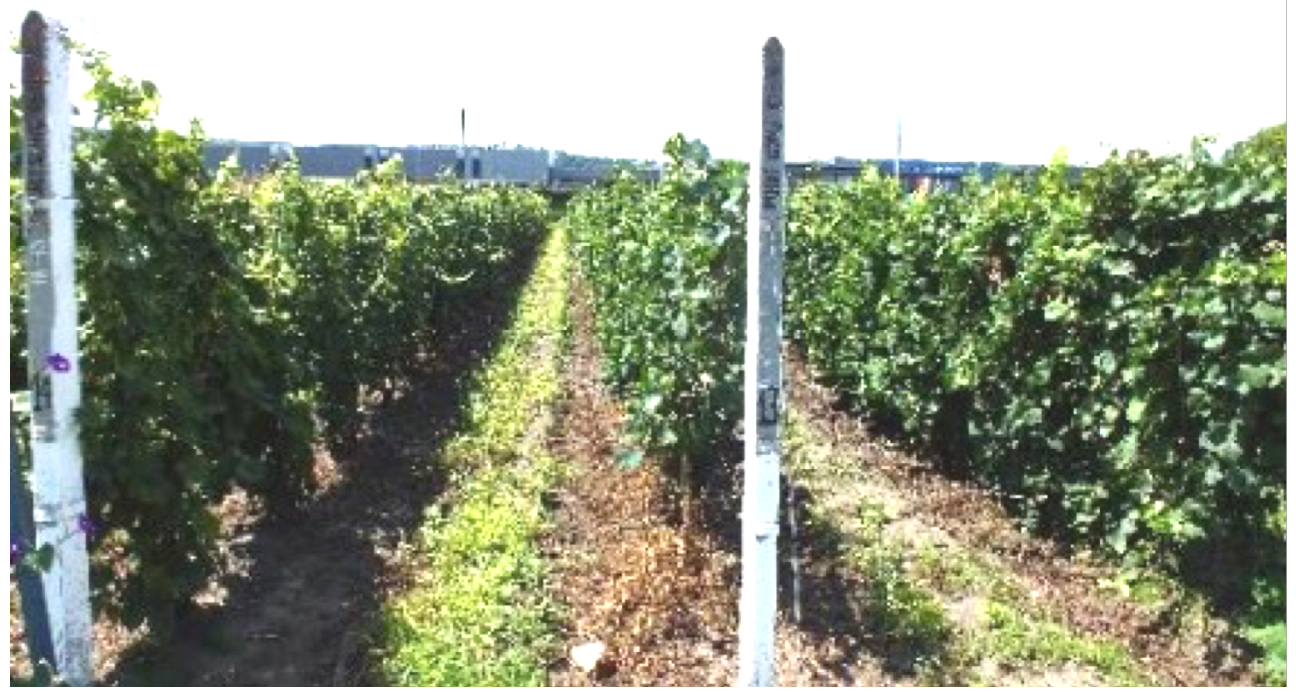

Fig. 1. Image from Blaj Wine Center's vineyard

Vineyard Center Blaj is representative of this prestigious wine-growing area but groves of this region, are dispersed in both latitude (between the parallel $46^{\circ}$ and 47 ${ }^{\circ}$ ) and altitude (more common between 200 and $500 \mathrm{~m}$ ), due to the fragmentation of the hilly and foothills of the plateau (Cudur et al. 2014).

From the environmental point of view, vines find here good conditions and a good growing season, especially in the South-Western half of the plateau which is referred to as ,wine country” (Cotea et al., 2003).

The importance of the Transylvanian Plateau wine region lies in both the areas planted with vines-vine, as well as in the quality of wines produced here, with wines of particular originality and nobility, from well-known varieties Fetească albă, Feteasca Regala varieties, italian Riesling, Sauvignon, Muscat Ottonel, Neuburger, etc. The grape varieties studied in this paper (Fetească regală, Sauvignon Blanc, Italian Riesling, Muscat Ottonel, Traminer roz) are the main white wine grape varieties grown in the Blaj wine center, as well as in all the Tarnave vineyards. 
The purpose of our article consists in the validation of the sensors and parameters employed and in the assessment of their relevance for the vineyard monitoring. In order to monitor the soil irrigation level, soil temperature, air temperature and humidity a series of IoT sensors are needed to detect the health of the vineyard. The accuracy of the measurement is essential in the analysis of soil quality and grape health. The monitored vine quality parameters depend on climate change and the climate of the region.

\subsection{Monitored parameters description}

\subsubsection{Soil Temperature and humidity}

The contactless sensor for measuring the temperature of a surface measures the electromagnetic radiation for each object with a temperature higher than the absolute zero temperature (used as a reference to calculate the temperature from a distance).

The sensor that determines the amount of water in the soil measures the potential and temperature of water in the ground and porous materials. Its extensive range makes this sensor ideal for measuring water potential in natural or other dry systems. Through the temperature measurements one determines the amount of water in frozen soils. Table 1 present the sensors specifications for temperature and humidity of soil.

Table 1. Sensors specification for temperature and soil humidity.

\begin{tabular}{|c|c|c|}
\hline $\begin{array}{c}\text { Temperature and soil } \\
\text { humidity }\end{array}$ & $\begin{array}{c}\text { Soil } \\
\text { temperature }\end{array}$ & Soil Humidity \\
\cline { 2 - 3 } & $\ddots$ & $\AA^{\ominus}$ \\
\hline Measurement range & $-50 \sim 300{ }^{\circ} \mathrm{C}$ & $0 \sim 200 \mathrm{cb}$ \\
\hline Accuracy & $\begin{array}{c} \pm 0.5^{\circ} \mathrm{C} \\
\text { accuracy from }- \\
10^{\circ} \mathrm{C} \text { to }+85^{\circ} \mathrm{C}\end{array}$ & $\begin{array}{c}50 \sim 10000 \mathrm{~Hz} \\
\text { approximately }\end{array}$ \\
\hline Resistance & $1000 \Omega$ & - \\
\hline Diameter & $6 \mathrm{~mm}$ & $22 \mathrm{~mm}$ \\
\hline
\end{tabular}

\subsubsection{Air temperature and relative air humidity}

The temperature and humidity in the atmosphere are measured using a single digital sensor capable of both operations. The humidity sensor offers a very low response time and very high overall accuracy over a wide temperature range. 
The integrated temperature sensor, managing to detect even the finest changes of the weather. Table 2 present the sensors specifications for temperature and humidity of air.

With the help of the sensor measurements described above and the data collected from them, the health of the vineyard was monitored for a chosen period of time.

\section{RESULTS AND DISCUSSIONS}

The analysis of the impact of physical parameters (soil and air humidity, soil and air temperature) on agriculture was realized in a vineyard area using Libelium Smart Agriculture Extreme, for two years, 2019 and 2020, from June to September.

Table 2. Sensors specification for temperature and air humidity.

\begin{tabular}{|c|c|c|}
\hline \multirow{2}{*}{$\begin{array}{l}\text { Temperature and air } \\
\text { humidity }\end{array}$} & Air temperature & Air Humidity \\
\hline & 0 & $\partial^{0}$ \\
\hline Measurement range & $-40 \sim+85^{\circ} \mathrm{C}$ & $\begin{array}{c}0 \sim 100 \% \text { of Relative } \\
\text { Humidity }\end{array}$ \\
\hline Accuracy & $0 \sim+65^{\circ} \mathrm{C}$ & $\begin{array}{c}< \pm 3 \% \text { RH }\left(\text { at } 25^{\circ} \mathrm{C},\right. \\
\text { range } 20 \sim 80 \%)\end{array}$ \\
\hline Response time & $\begin{array}{c}1.65 \text { seconds } \\
(63 \% \text { response } \\
\text { from }+30 \text { to }+125 \\
\left.{ }^{\circ} \mathrm{C}\right) .\end{array}$ & 1 second \\
\hline
\end{tabular}

The data acquired from the agricultural sensors were centralized into a database. One highlighted the impact of measured parameters on grapes. The variation of the measured parameters is presented in Fig.3, Fig.4, Fig. 5 and Fig.6.

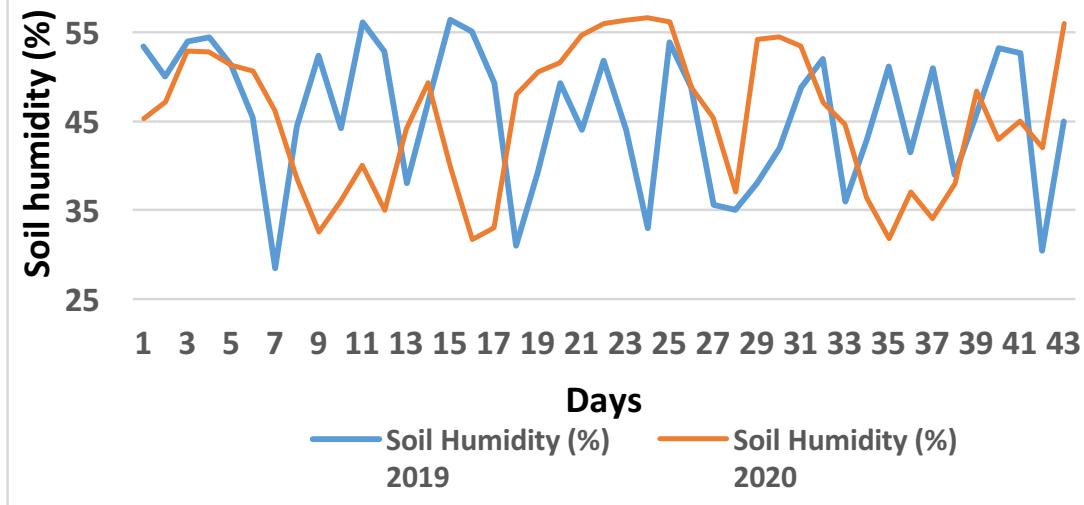

Fig. 3. Variation of soil humidity, comparison between 2019 and 2020 
Fig. 3 presents the variation of soil humidity. The results were obtained for a depth of $25 \mathrm{~cm}$. In both seasons of the two years (2019 and 2020) the humidity of the soil had values above $35 \%$, but there were also isolated values lower than $35 \%$, especially in 2019 , where the humidity was quite low. This does not affect the quality of the vineyard because the soil has provided the requisite water for healthy growth.

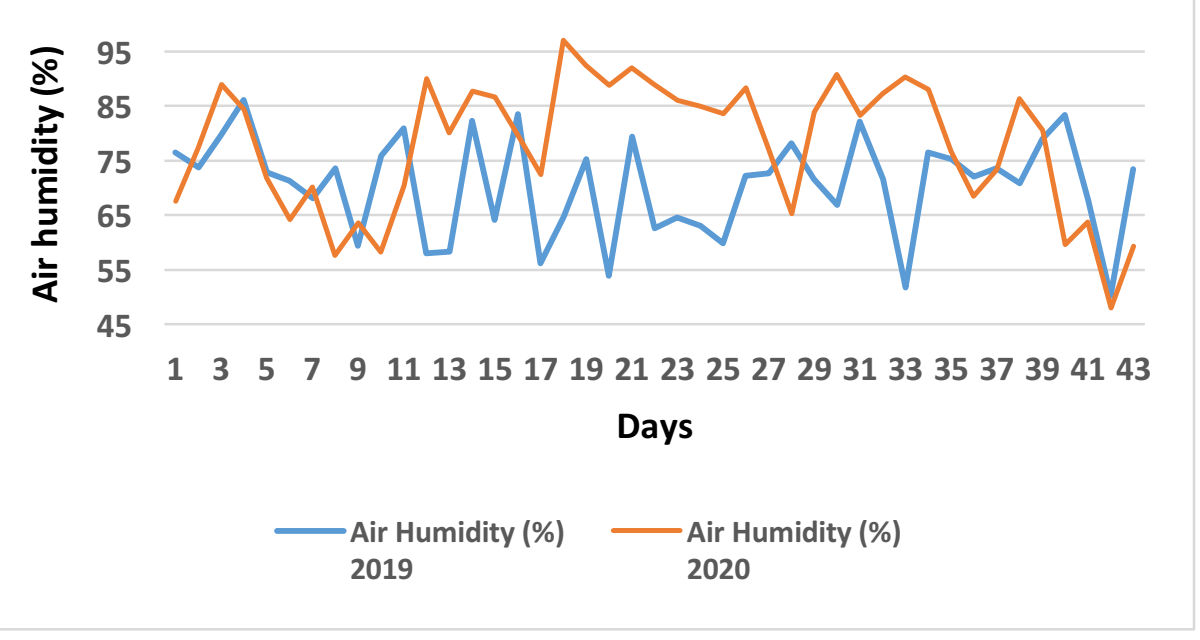

Fig. 4. Variation of air humidity, comparison between 2019 and 2020

Fig. 4 highlights the air humidity in 2019 and 2020. In 2020, the air humidity was in the interval $50-86 \%$, while in 2020, the air humidity ranges between 47 and $97 \%$. The optimal relative humidity, though, is between 55 and 65\% (Irimia 2012), above this interval the germination of vineyard diseases is highly intensified (Caroll and Wilcox 2003).

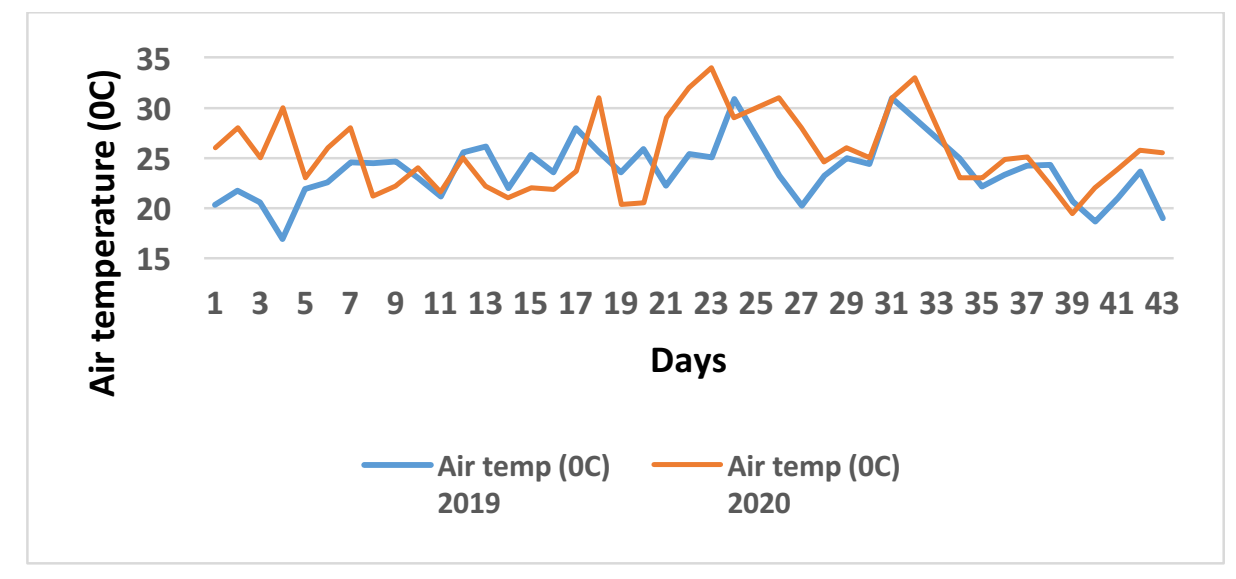

Fig. 5. Variation of air temperature, comparison between 2019 and 2020 
In Fig. 5, one represented the comparison between the air temperature evolution in 2019, and respectively, 2020. The high values of air temperature may determine high vapour pressure deficit (VPD) conditions if the air relative humidity is low.

Temperature afflicts grape growing, composition and quality. We remark that 2020 season was more favourable to grape's growing, due to the fact that the temperature values were more often in the proper intreval $25-32^{\circ} \mathrm{C}$.

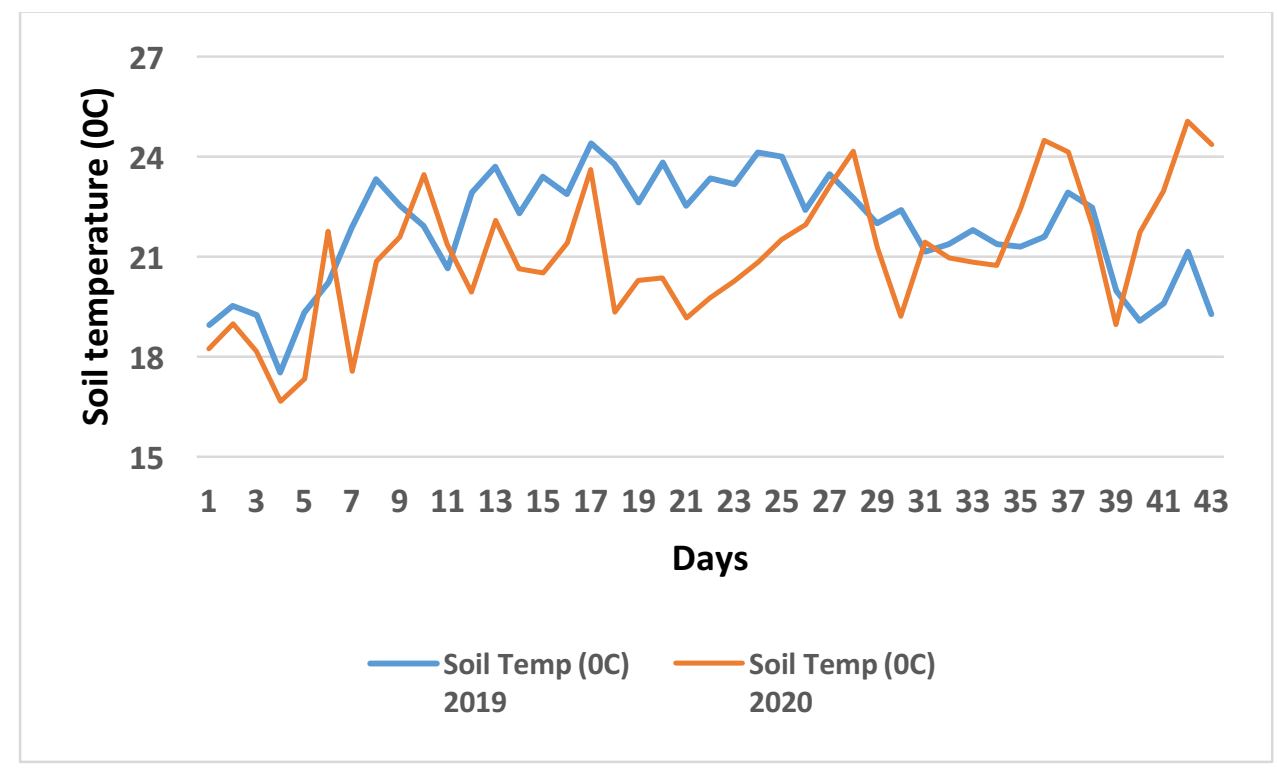

Fig. 6. Variation of soil temperature, comparison between 2019 and 2020

As in the case of the soil moisture sensor, the results for the soil temperature sensor were obtained for a depth of $25 \mathrm{~cm}$. Fig. 6 reveals again that both 2019 and 2020 seasons were suitable for grape cultivation in the proposed vineyard, as the soil temperature ranged between $17.52^{\circ} \mathrm{C}$ and $24.40^{\circ} \mathrm{C}(2019)$, respectively $16.54^{\circ} \mathrm{C}$ and $25.07^{\circ} \mathrm{C}(2020)$ which are optimal conditions for not developing, for example, plant parasitic nematodes (Ferris et al 2013).

A descriptive statistic was performed for a better analysis of the measured values for soil humidity, leaf wetness, and temperatures for the two years (2019 and 2020). Table 3 presents the statistical analysis.

The analysis reveals that the values of the monitored parameters are quite close in value, which indicates that the values are valid and analyzes the health of the vine culture. 


\section{CONCLUSIONS}

The main conclusion following the experiments outlines that the implemented field monitoring platform based on IoT technologies can lead to useful and accurate precision in monitoring, analyzing, assessing, and controlling agricultural fields. The platform system has performed automatic monitoring of the environmental temperature and humidity of soil and air and soil humidity.

Table 3. Statistical analysis for soil humidity, leaf wetness and temperature timing of air and ground frost in the years 2019 and 2020

\begin{tabular}{|c|c|c|c|c|c|c|c|c|}
\hline \multirow{2}{*}{$\begin{array}{c}\text { Statistical } \\
\text { parameters }\end{array}$} & \multicolumn{2}{|c|}{$\begin{array}{c}\text { Soil } \\
\text { humidity }\end{array}$} & \multicolumn{2}{|c|}{$\begin{array}{c}\text { Air } \\
\text { humidity }\end{array}$} & \multicolumn{2}{|c|}{$\begin{array}{c}\text { Soil } \\
\text { temperature }\end{array}$} & \multicolumn{2}{|c|}{ Air temperature } \\
\hline & 2019 & 2020 & 2019 & 2020 & 2019 & 2020 & 2019 & 2020 \\
\hline Mean & 45.77 & 45.40 & 21.82 & 21.06 & 21.82 & 21.06 & 23.79 & 25.54 \\
\hline Standard Error & 1.17 & 1.20 & 0.25 & 0.30 & 0.25 & 0.30 & 0.45 & 0.57 \\
\hline Median & 47.27 & 46.25 & 22.31 & 20.97 & 22.31 & 20.97 & 23.69 & 25 \\
\hline Standard Deviation & 7.69 & 7.87 & 1.69 & 2.01 & 1.69 & 2.01 & 2.96 & 3.75 \\
\hline Sample variation & 59.20 & 62.04 & 2.85 & 4.05 & 2.85 & 4.05 & 8.81 & 14.08 \\
\hline Minimum & 28.46 & 31.67 & 17.52 & 16.67 & 17.52 & 16.67 & 16.95 & 19.43 \\
\hline Maximum & 56.37 & 56.62 & 24.40 & 25.07 & 24.40 & 25.07 & 31 & 34 \\
\hline $\begin{array}{c}\text { Confidence Level } \\
(95.0 \%)\end{array}$ & 2.36 & 2.42 & 0.52 & 0.61 & 0.52 & 0.62 & 0.91 & 1.15 \\
\hline
\end{tabular}

These factors and field conditions are monitored continuously from seeding to harvesting. The existence of these data transmission systems highlights the knowledge of the soil-plant-atmosphere interactions needed to optimize agricultural production. The system's novelty consists of solar energy use that powers the entire system, along with dedicated sensors. 
As future work, we want to create a mobile application to help the farmers monitor the physical parameters for good and healthy grapes.

\section{ACKNOWLEDGEMENTS}

This work was supported by a grant of the Romanian Ministry of Research and Innovation, CCCDI - UEFISCDI, project number EUROSTARS-2019-E!113655DISAVIT, within PNCDI III.

\section{REFERENCES}

1. Calugar, A., Babes, A.C, Bunea, C.I., Pop, T.I., Tomoioaga, L. and Iliescu, M. (2018) Oenological characterization of wines from grape clones created at Research Station for Viticulture and Enology Blaj. Stiinta agricola, 2, 50-56.

2. Carroll, J. E., and Wilcox, W. F. (2003). Effects of humidity on the development of grapevine powdery mildew. Phytopathology 93, 1137-1144.

3. Cotea, D.V., Barbu, N., Grigorescu, V.V. (2013). Romanian vineyards and wines. The Romanian Academy's Publishing House, Bucharest

4. Cudur, F., Iliescu, M., Comsa, M., Popescu, D. and Cristea, C. (2014). Soil Type Influence on Yield Quantity and Quality at Grape Varieties for White Wines Obstained in the Viticultural Centre Blaj. Bulletin of Agricultural Sciences \& Veterinary Medicine Cluj-Napoca. Horticulture, 71(1).

5. Ferris, H., Zheng, L., \& Walker, M. A. (2013). Soil Temperature Effects on the Interaction of Grape Rootstocks and Plant-parasitic Nematodes. Journal of nematology, 45(1), 49-57.

6. Ieremia, L. (2012). Biologia viţei de vie (Biology of the grapevine). Unpublished. https://doi.org/10.13140/2.1.3909.9205

7. Irimi, L. M., Patriche, C. V., Quénol, H., Planchon, O., \& Sfâcă, L. (2015). Characteristics of the baseline climate of the Cotnari (Romania) wine growing region.

Cercetari Agronomice in Moldova, 47(4), 99-111.

8. Lee M., Hwang J., Yoe, H. (2013) Agricultural Production System Based on IoT, 2013 IEEE 16th International Conference on Computational Science and Engineering, Sydney, NSW, 833-837.

9. Libelum's new Smart Agriculture Extreme Sensor Node Provides Maximum Accuracy for Crop Monitoring, http://www.libelium.com/libeliums-new-smart-agriculturextreme-sensor-node-provides-maximum-accuracy-for-crop-monitoring/, (accessed on October 2020).

10. Oliver S. T, González-Pérez A., Guijarro J. H (2018). An IoT proposal for monitoring vineyards called SEnviro for agriculture. Proceedings of the 8th International Conference on the Internet of Things, 1-4.

11. Pérez-Expósito J. P., Fernández-Caramés T. M., Fraga-Lamas P. and Castedo L. (2017) An IoT Monitoring System for Precision Viticulture, 2017 IEEE International Conference on Internet of Things (iThings) and IEEE Green Computing and Communications (GreenCom) and IEEE Cyber, Physical and Social Computing (CPSCom) and IEEE Smart Data (SmartData), Exeter, 662-669. 
12. Tonietto, J., Carbonneau, A. (2004) A multicriteria climatic classification system for grape-growing regions worldwide, Agricultural and Forest Meteorology, 124(1-2), 81-97.

13. Trilles S., Torres-Sospedra J., Belmonte O., Zarazaga-Soria F.J, Gonzalez-Perez A., and Huerta J.(2020) Development of an open sensorized platform in a smart agriculture context: A vineyard support system for monitoring mildew disease. Sustainable Computing: Informatics and Systems, 28(100309). 